\title{
Success Factors of Mixed-Use Building Construction Project: A Case of Arada Sub-City, Addis Ababa
}

\author{
Kidanemariam Sileshi Gebretsadik ${ }^{1}$, Melkamu Tadesse Wazza ${ }^{2, *}$ \\ ${ }^{1}$ Department of Project Management, PBT Africa College, Addis Ababa, Ethiopia \\ ${ }^{2}$ Post-Graduate College of Project, Business and Technology, PBT Africa College, Addis Ababa, Ethiopia
}

Email address:

sileshikid@gmail.com (K. S. Gebretsadik), pbtafrica.college@gmail.com (M. T. Wazza)

${ }^{*}$ Corresponding author

To cite this article:

Kidanemariam Sileshi Gebretsadik, Melkamu Tadesse Wazza. Success Factors of Mixed-Use Building Construction Project: A Case of Arada Sub-City, Addis Ababa. American Journal of Civil Engineering. Vol. 9, No. 6, 2021, pp. 221-235. doi: 10.11648/j.ajce.20210906.15

Received: October 13, 2021; Accepted: November 11, 2021; Published: December 31, 2021

\begin{abstract}
The construction sectors project implementation is realized by which it undergoes many problems, difficulties and highly complicated process from inceptions to completion. Ethiopia's construction projects are highly subjected to cost and schedule overrun and developing success factors as early as possible is a pressing issue. The objective of this paper is to determine the most significant success factors of mixed use building construction project using quantitative statistical method. Data collected from different respondents through questionaries' analyzed using RII. Based on the RII result General Project management Related success factors becomes the leading than other success factor group. This group is more general and shared by all stakeholder and considered in each phase from initiation to the end. Followed by Environment, Client, Consultant and contractor related major success factor groups respectively. All the aggregated list of success factor has a significant factor for the success. Most important success factors are: Lessons learned from previous project, having qualified and specialized personnel, clearly defining project scope, Consistency of currency price \& stability of national economy, Material and equipment availability, Conducting On-job research, Consultant commitment to ensure construction work. Identifying success factors with respect to each stakeholders and phases will benefit a lot to do their best at each stage of the project. Learning from previous work, having qualified and specialized personnel and defining scope clearly should have to be the core of project participant at each stage of construction project to accomplish successfully.
\end{abstract}

Keywords: Success Factors, Stakeholders, Phases

\section{Introduction}

\subsection{Brief Background}

The construction industry plays a vital role for the overall socio-economic development of a country. Ethiopia is the fastest growing, non-oil driven economy among African countries. The country showed a remarkable growth over the past ten years, the annual GDP is $10.9 \%$ as per the UNDP report of 2014. But, the contribution of the construction industry against the GDP is only $3 \%$ and this is lower than the Sub-Saharan Africa average which is $6 \%$.

Project implementation is realized by which it undergoes difficulties and highly complicated process from inceptions to end. Of course Construction projects are often initiated and executed in the context of a turbulent, unpredictable and dynamic environment.

Project success factors are factors when present improve the likelihood that projects will be implemented successfully. Kerzner [8] defined project success factors as "elements required to create an environment where projects are managed with excellence".

Construction projects are influenced by both external and internal factors. Managing those factors and becoming successful requires a lot from the participant.

\subsection{Problem Statement}

As Worku Koshe and Jha K. N [15] has defined a construction project is acknowledged as successful, when it is completed on schedule and within the sated budget initially, agreed quality and in accordance with the 
specification and to the stakeholders' satisfaction.

There are a lot of reasons for the failure of projects on different stages of implementation. The main reasons for the failure of project in developing countries are: poor preconstruction activities, lack of adequate and well organized planning at the start, lack of a systematic and holistic methodology, lack of comprehensive engineering system and professionals, inconsistency in monitoring internal \& external stakeholders, coordination \& communication lapses and above all absence of a methodical and well organized approach in identifying and monitoring the success factors.

Number of construction project to fall behind their targets in Ethiopia. Ayalew et al [2] described that the amount of schedule slippage ranges between $61-80 \%$ and that of planned costs and other variables such as risk, quality and safety deviates in the range $21-40 \%$ from predetermined requirements at the beginning. To be more specific let us look at the Arada sub-city Building construction status for those building project who got construction permit in 2012 and 2013.

Table 1. Status of Mixed-Use Building Construction Project relative to the schedule.

\begin{tabular}{lll}
\hline Status & Amount & $\mathbf{\%}$ \\
\hline Completed & 3 & $12.5 \%$ \\
Active & 16 & $66.7 \%$ \\
Terminated + Delayed & 5 & $20.8 \%$ \\
Total & 24 & $100 \%$ \\
\hline
\end{tabular}

Source: Arada Sub-City Administration Construction Permit and Regulatory Office.

Table 2. Status of Mixed-Use Building Construction Project to the Initial Budget.

\begin{tabular}{lll}
\hline Status & Amount & \% \\
\hline Under budget & 0 & $0 \%$ \\
Within budget & 7 & $29.1 \%$ \\
Over budget & 17 & $70.9 \%$ \\
Total & 24 & $100 \%$ \\
\hline
\end{tabular}

Source: Arada Sub-City Administration Construction Permit and Regulatory Office.

The amount of projects failed is around $21 \%$. When it comes to planned cost the deviation goes around $71 \%$ (overbudget). This indicates that the construction projects are highly subjected to cost overrun and failures. Proper identification of success factors is crucial. Therefore, this assessment is intended to identify key success factors. The fact that the construction industry suffers the most to meet the deadlines and budgets necessitates a great attention to identify critical success factors.

\subsection{Research Objectives}

The objective is to identify success factors of construction project, that directly help the firm in implementation and execution of the Mixed-use building construction project in Arada Sub-city successfully. In line with the above objectives, this work will also seek to rank and categorize the success factors in their respective groups to be implemented by stakeholders in each phases of the construction.

\subsubsection{General Objectives}

The General objectives is to Assess success factors of Mixed-Use Building Construction Project in Arada Sub-City, Addis Ababa.

\subsubsection{Specific Objectives}

a) To identify the potential success factors of Mixed-Use Building Construction Project in Arada Sub-City, Addis Ababa.

b) To determine the contribution and rank to the factors based on their RII.

c) To categorize them based on the phases of building construction and to the stakeholders they belong.

\subsection{Research Question}

The following question will be addressed using the pertinent research instruments, namely:

1) What are the potential success factors of Mixed-Use building construction project in Arada Sub-City, Addis Ababa?

2) What are their ranks? which factors are perceived the most significant and which factors are less significant?

3) To what major categories they belong, based on stakeholders and phases of construction?

\subsection{Significance of the Study}

This study helps in reducing project failures by introducing potential success factors for the construction project. It will enable the new project to successed by giving direction and giving guidelines. The research will update and bring success factors of mixed-use building construction project and try to come up in formulating better practical recommendation.

\subsection{Scope of the Study}

The scope of the study is limited to Assessing the potential success factors of mixed-use building construction project in Arada Sub-City, Addis Ababa. It will assess cumulative experience from the past, mainly focusing on current practices and prospects in the future.

Temporal Scope: The research reviews the project who got construction permit in 2012 \& 2013 E.C. in Addis Ababa, Arada Sub-City.

Methodological Scope: only quantitative analysis after literature review and surveys considered.

\subsection{Limitation of the Study}

1) Each and every project is unique by its nature and it is hard to make a generalization on the success factors for building projects based on this research work.

2) It is hard to investigate success factors only by focusing on succeed project rather I preferred to make my focus on participants. Respondents are expected to answer the questionnaires by bearing in mind their experience so far by incorporating with their knowledge on the topic area and the current project they are participating. So the result is all about on respondents thinking. 


\section{Literature Review}

\subsection{Theoretical Literature Review}

\subsubsection{Project Success}

Even if it is difficult and complex to define the term "success" in the construction perspective. The factors for success are even more unpredictable. Davis [6] indicated that within the last decades the concept of project success is approached in relationship with stakeholders' perception and being accepted that success means different to different people. In modern project management client acceptance for the executed work is the major success criteria.

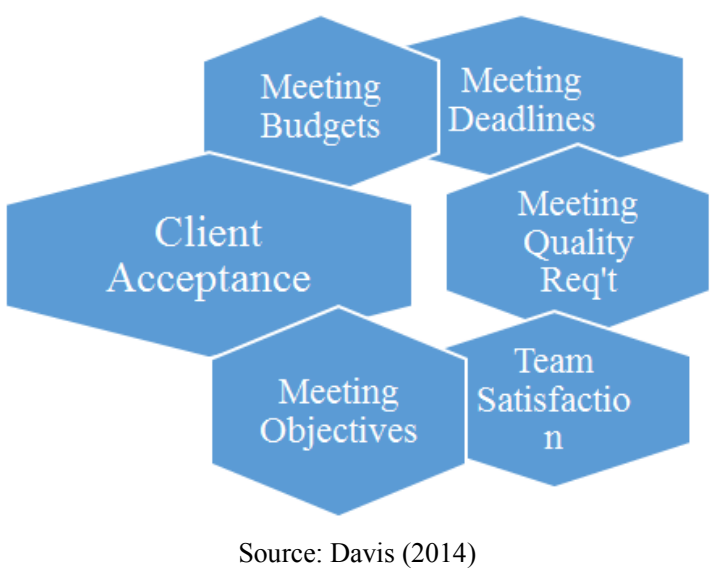

Figure 1. Project Success Definition.

\subsubsection{Construction Project Success}

So far there is no accepted universally agreed single definition of project success according to Nguyen T. A. and Chovichien V. [12] Definition and criteria of project success may vary depending on the industry types, project types, project teams, clients, professionals and point of views. But in more general way there is one definition which may create a common understanding; "The project is considered as successful if the project meets the technical specification and mission to be performed by project and if there is high level of satisfaction concerning the project outcome among key people in the part of organization, key people in the project team and key users or clients of the project effort". According to this concepts, a project should satisfy the key people within the parties in addition to the fulfillment of the technical specification and meet the triple constraints (time, cost and quality).

\subsubsection{Critical Success Factors}

Chan et al [4] identified a number of variables influencing the success of project implementation. They suggested that Critical Success Factors can be grouped under four main categories: Human Related Factors, Project Related, Project Procedures and Project Management Action. After identifying various factors affecting projects the variables with each group are interrelated to know their relationship and to study how those factors affect project success separately and collectively, it is hypothesized in the above categories. They also developed a new conceptual framework that includes and regroups the identified variables affecting the success of project.

Project, Client, Contractor, Consultant and supply chain related factors affect the performance of project implementation as per the Tsedenya Y. [14] study.

When it comes to the personnel related factors the ability of the project managers to perform the other facilitating knowledge areas namely, project integration, human resources management, communications management, risk management and procurement management as well as make use of project management tools and techniques were found to have a bearing on the ability to deliver projects successfully as per the investigation made by Nehemiah $\mathrm{M}$ et al [11].

\subsection{Empirical Literature Review}

Based on the quantitative research they performed Ioana B. et al [7] obtained significant result. After intensive literature review and well organized questionnaires they get meaningful rank. Respondents were asked to choose from the list of factors presented. Since all tare relevant to the project's success, it can be observed that each of them received votes. Based on the results of the questionnaire, the three factors with highest impacts on project are: Clearly defined goal and direction $\left(1^{\text {st }}\right)$, Competent project team members $\left(2^{\text {nd }}\right)$ and Clearly defined roles and responsibilities $\left(2^{\text {nd }}\right)$,

Table 3. Ranking of Success Factors.

\begin{tabular}{lll}
\hline Success Factors & Choice & $\mathbf{\%}$ \\
\hline Compliance with budget \& time. & 19 & 40.4 \\
Clearly defined goals and directions & 33 & 70.2 \\
Accurate schedule & 17 & 36.2 \\
Competent team members & 25 & 53.2 \\
Clearly defined roles and responsibilities & 25 & 53.2 \\
\hline
\end{tabular}

Source: Beleiu, Crisan and Nistor (2014).

Based on their investigation Mammaru D. et al [9] find out and able to categorize the significant success factors in governmental building construction project.

1) Management Related Success Factors:

Table 4. Management Related Success Factors.

\begin{tabular}{llll}
\hline Types of Factors & Mean & RII & Rank \\
\hline Decision making Effectiveness & 4.481 & 0.896 & 1 \\
Project Monitoring & 4.444 & 0.889 & 2 \\
Planning Effort & 4.309 & 0.862 & 3 \\
\hline
\end{tabular}

Source: Mammaru Dessalegn, et al (2017).

Decision making effectivenes from inception of project to the end will encourage for the succcesfulness of project. During the execution of the overall project; monitoring each and every activities are expected from all participants.

"If you fail to plan you are planning to fail"; planning is a pilar for the success of construction project. From the experience and by using some techniques and tools having realistic plan will lead the project for success. 
2) Purchasing Related Success Factors:

Table 5. Purchasing Related Factors Variables.

\begin{tabular}{llll}
\hline Types of Success Factors & Mean & RII & Rank \\
\hline $\begin{array}{l}\text { Project delivery system (ex: Design-Bid-Build, DB) } \\
\text { Project bidding method (ex: price based }\end{array}$ & 4.247 & 0.849 & 1 \\
competitive bidding, negotiated bidding) & 4.099 & 0.820 & 2 \\
\hline
\end{tabular}

Source: Mammaru Dessalegn, et al (2017).

While each project team generally consists of an owner, a designer, and a builder, how each project is executed differs. Choosing the right project delivery method is a crucial step before design begins, as it sets the tone for how the team will communicate and how payments will be distributed.

3) Client Related Factors: funding issue always belongs to the client directly. The client characteristics, client type, experience and wants are mainly focused.

Table 6. Clients Related Factors Variables.

\begin{tabular}{llll}
\hline Types of factors & Mean & RII & Rank \\
\hline Timely decision by the clients & 3.951 & 0.790 & 1 \\
Clear definition of project scope & 3.926 & 0.785 & 2 \\
Clients confidence & 3.901 & 0.780 & 3 \\
\hline
\end{tabular}

Source: Mammaru Dessalegn, et al (2017).

Client or owner is the main source of finance in each project. The ability of clients decision making play great role for the effective accomplishement of the construction project. Defining the scope of the project and their interests clearly will enable to the overall implementation smoothly. In addition consistency in decision also expected form clients.

4) Contractor Related Success factors:

Table 7. Contractors related Factors Variables.

\begin{tabular}{llll}
\hline Types of factors & Mean & RII & Rank \\
\hline Cash flow & 4.407 & 0.881 & 1 \\
Site management & 4.395 & 0.879 & 2 \\
Experience & 4.333 & 0.867 & 3 \\
\hline
\end{tabular}

Source: Mammaru Dessalegn, et al (2017).

Contractor is the one who will execute the work. Having adequate and healthy cash flow will enable to supply the required equipment, materials and personnels on required time and place. Experience highly increase the success accomplishment of the construction project. As there are different activities which are repetitive and similar having experience in this area will help in increasing the effectiveness.

5) Environment Related Success Factors:

Table 8. Environmental Related Factors.

\begin{tabular}{llll}
\hline Types of Factors & Mean & RII & Rank \\
\hline Adequacy of funding & 4.481 & 0.896 & 1 \\
Technology availability & 4.296 & 0.859 & 2 \\
Economic environment & 4.235 & 0.847 & 3 \\
\hline
\end{tabular}

Source: Mammaru Dessalegn, et al (2017).

Adecuency of funding and price stability within the country will enable the contractor to execute the work as per the agreed price. Advance techonolgy enhancement will be a cataelyst for the efective execution of the work.

The sudy conducted by Alias et al [1] also illustrated that the basic variables for project success are: project management action, project procedure, human related factors, project and environment related factors.

\subsection{Conceptual Framework}

Based on literature review and my experience it is better to consider those factors based on key stakeholders to which they belong. These will greatly help for each stakeholder to do their best what expected from them. Client, consultant and contractors play a significant role. In addition, external environment has also a potential factor directly. Considering General project management related factors as a frame also necessary which is shared by all stakeholders at each phases of construction. Planning and implementing each and every phases properly will result in the success of project.

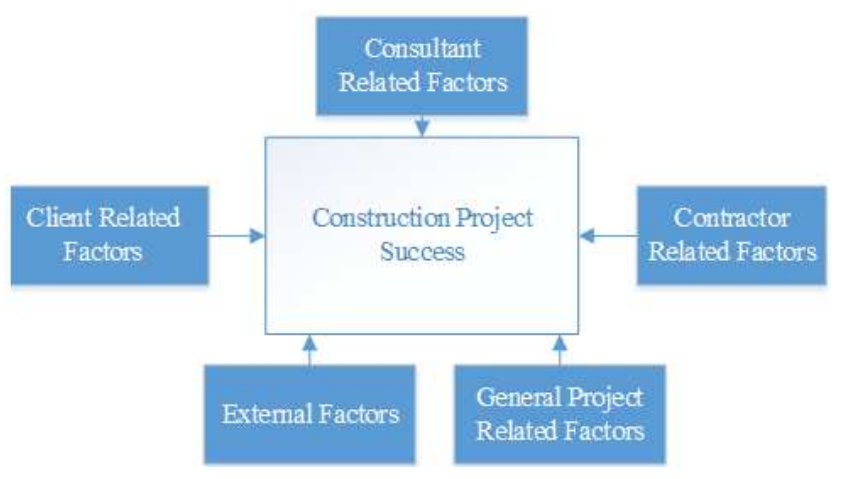

Figure 2. Success factors conceptual framework.

\section{Research Methodology}

According to Cooper and Schindler [5] the next step in the research process after studying the literature, finding 'management dilemma' and identifying the research questions is deciding on suitable methodology.

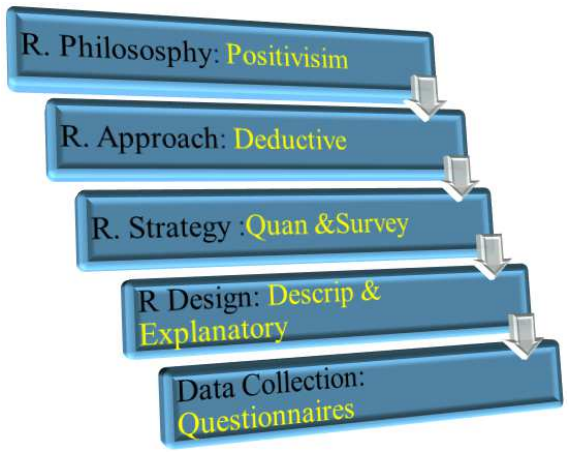

Figure 3. Research methodology approach.

\subsection{Research Philosophy}

Scholar's like Ticehurst \& Veal [13] claims that there is a frequent overlap and similarity in between Positivism and 
Interpretivisim. But due to the turbulent construction environment, its complexity and uniqueness even a threemonth study might be not relevant in current situation to adopt Interpretivisim theories. Even though the research question of this study has a primary focus on the detail and single success factors aspects positivism research philosophy is chosen. Considering different mixed-use building project in Arada sub-city by concentrating on different list of success factors seems a little bit impossible to drive a general conclusion about the sector in general. But to be more realistic making the scope specific and employing statistical techniques becomes more useful to gather facts to make this type of generalization.

Positivism highly relies on experience as a valid source of knowledge in this regard having experienced professionals from different stakeholder on the topic is possible. Of course positivism lacks insight into in-depth issues but the research findings is all about descriptive.

\subsection{Research Approach}

Deductive approach to research is seen as one of the main principles of positivism research philosophy and it is the most appropriate for our case. The research process begins with analysis of literature which is directly related to the success of construction projects. In addition, site visit and observation is conducted to get the full list of the success factors. As a result of review of numerous articles and conducted survey an aggregative list of success factors was formed in tabular form (see Appendix 1).

\subsection{Research Strategy}

C1. Quantitative: Since the study is finding success factors $\&$ exploiting some unique trends in categorization and giving ranks, so a quantitative method used.

C2. Types of research strategy: Survey is chosen because it allows to collect a large amount of data and allows the researchers to control the study. Site visit and survey chosen as a data collection to exploit the research area in depth and to add knowledge to the existing success factors on the previous literature. Then a questionnaire distributed among different stakeholders who directly involved directly.

\subsection{Research Design}

The research employs both Descriptive and Explanatory studies in order to conduct a proper research based on the factors list and variables relationship established. Descriptive designs used in order to analyze the rank of the success factors for the mixed-use building construction project in Arada sub-city, Addis Ababa identified by the aggregated literature review and survey. Explanatory design involved since one of the aims of this research is to find relationship between different factors and categorizing them in their respective group and phases of construction. A descriptive design sought to give causal relationship between the success of mixed use building construction which is dependent variable on aggregated list of success factors.

\subsection{Data Collection Instruments and Procedure}

Self-completion paper based questionnaires to collect appropriate data has selected. Both open and closed ended questions distributed to contractor, consultant, local construction admin and client's representatives as a primary source of data. The questionnaires presented 82 success factors incorporated from literature and site survey. After modification and reduction with proper scrutiny of each success factors questions structured into 5 major success factor group as Client, Consultant, Contractor External Environment and General Project Management related factors. The first three categories further assessed at different phases. After the approval of questionnaires by the advisory actual distribution of questionnaires to the respondents followed. The Consultants, contractors and local construction admins able to understand the survey. Questionnaires are interpreted in Amharic as an option for clients.

\subsection{Operationalization of Variables}

The dependent variable is success of mixed-use building construction project in Arada sub-city Addis Ababa. Those 82 aggregated success factors which are independent variables, but on the questionnaires there is an open space which invites the respondents to add more success factors.

Table 9. Operationalization of variables.

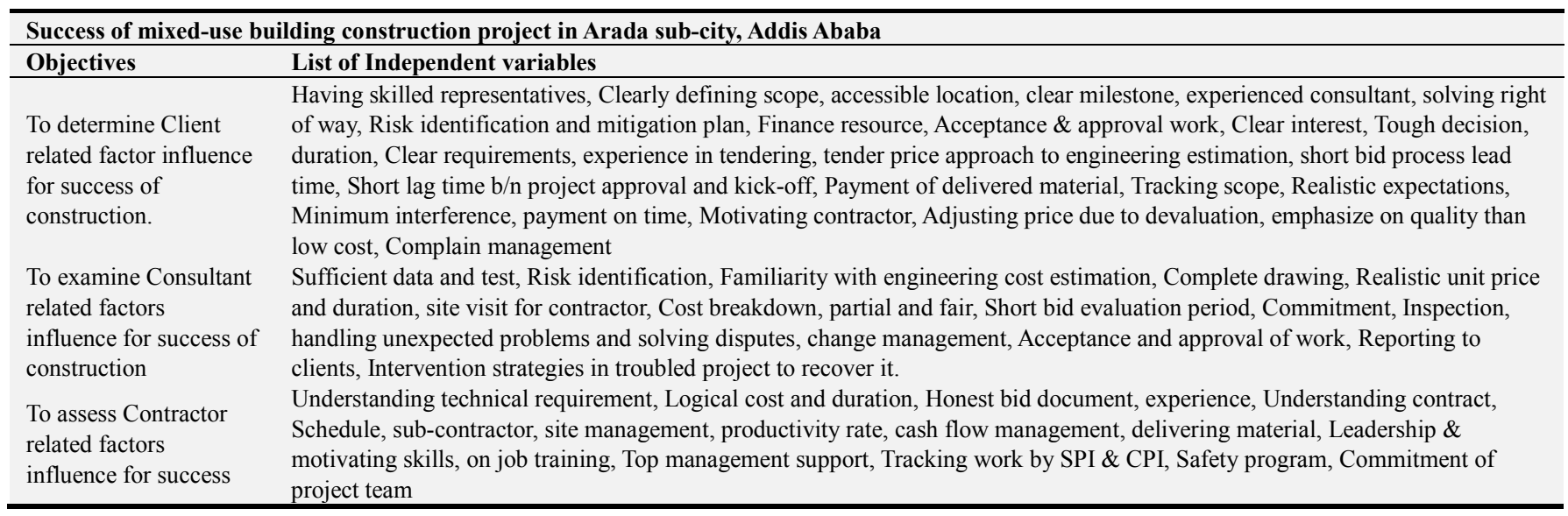




\begin{tabular}{ll}
\hline Success of mixed-use building construction project in Arada sub-city, Addis Ababa \\
\hline Objectives & List of Independent variables \\
\hline $\begin{array}{l}\text { External Environment } \\
\text { factors for the success }\end{array}$ & $\begin{array}{l}\text { Technology advancement, Consistency of currency, Skilled labour availability, Acceptance by Social norms, Stable political } \\
\text { condition, Predictable weather, Clear tendering law, Short process to get permit \& support from local administration, Material } \\
\text { equipment availability, Financial \& market stability }\end{array}$ \\
$\begin{array}{l}\text { General Project } \\
\text { Management factors } \\
\text { for the success. }\end{array}$ & $\begin{array}{l}\text { experience, Good documentation, detailed procedure \& communication, Proper construction methodology, Qualified personnel, } \\
\text { Clear responsibility demarcation, Training, Making trade-off on constraints, Reward and recognition }\end{array}$ \\
\hline
\end{tabular}

\subsection{Description of the Study Area}

Arada is one of the 11 sub-cities of Addis Ababa, Ethiopia. Arada is known as center of the old and the new generation artistic, social and urban life styles.

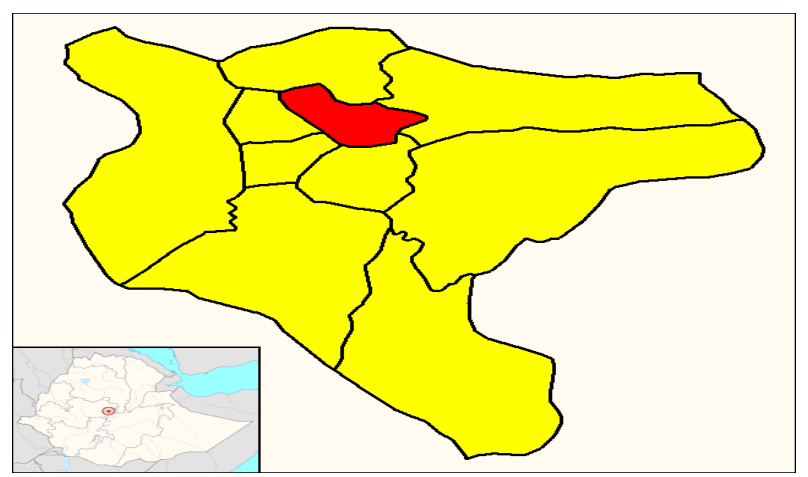

Figure 4. Map of Addis Ababa, Arada Sub.

Table 10. Types of building under construction in Arada Sub-City (2012 \& 2013).

\begin{tabular}{lll}
\hline Types of Building & Amount & $\mathbf{\%}$ \\
\hline Mixed-Use Building & 24 & $54.5 \%$ \\
Apartment Building & 8 & $18.2 \%$ \\
Living Building & 9 & $20.5 \%$ \\
School \& Guest House & 3 & $6.8 \%$ \\
Total & 44 & $100 \%$ \\
\hline
\end{tabular}

Source: Arada Sub-City Administration Construction Permit and Regulatory Office.

\subsection{Target Population, Unit of Analysis and Sample Size}

Due to the nature of data to be collected from large population probability sampling method adopted to be more inclusive. The target populations of this study are those who are directly participating in the mixed use building construction project: clients, consultants, contractor and local construction administration office engineers.

Expected population size is all about who does fit for being the target group? For this study we do have 4 groups of stakeholders as a primary source for data. Those 24 mixed use building construction who get the construction permit in 2012 and 2013 are the scope of the study. From this we do have 24 clients or representative. But for the consultant and contractors case to get the number of population size representation during site visit and survey counting the professionals and estimating the average was the options. The result is 1 consultant professionals (Resident Engineer) and two contractor professionals for one project. And there 13 construction administration office engineers in Arada sub city on job who have a direct responsibility and mandate regarding those construction project in the sub-city. Source: Field Survey (2021)

$$
\text { Expected population size }=24+24 *(1+2)+13=109
$$

Neither too small nor too big sample size which is appropriate and logical are needed to yield statistically significant result. Population size is 109 .

Margin of error; The selected margin of error is $\pm 5 \%$.

Confidence level: $95 \%$ is selected that actual mean falls within the margin of error and Standard deviation. let's take 0.5 to make sure in having enough sample. Z-Score is taken in relation with the selected confidence level. For achieving $95 \%$ of confidence level Z-Score belongs to it is 1.96 .

Table 11. Z-Score for common confidence level.

\begin{tabular}{ll}
\hline Confidence Level & Z-Score \\
\hline $90 \%$ & 1.645 \\
$95 \%$ & 1.96 \\
\hline
\end{tabular}

Sample size executed using Wiliams sample size estimation method as it best suited in specifying confidence level and helps to understand clearly how sample size of infinite population is executed and then adjusted.

$$
\begin{gathered}
\text { Ideal SS }=\frac{(Z \text {-Score })^{2} * \text { Standard Deviation } *(1-\text { Standard Deviation })}{(\text { Margin of error })^{2}} \\
=\frac{(1.96)^{2} * 0.5 *(1-0.5)}{(0.5)^{2}}
\end{gathered}
$$

$=384.16 \ldots$ SS for infinite population

Adjusting to the required population using 109 population

$$
\begin{gathered}
\mathrm{SS}=S S / 1+[(S S-1) / P] \\
=384.16 / 1+[(384.16-1) / 109] \\
=85.98 \approx 85
\end{gathered}
$$

\subsection{Flow and Data Analysis Techniques}

Aggregated list of success factors structured into questions with Likert's scale response alternatives for the sake of doing quantitative analysis by RII. Success factor categorization into Client related, Consultant related, Contractor related, External Environment and General Project Management related factors.

The first step after collecting data in the form of questionnaires from respondent was coding each questions 
by assigning letters incorporated by numbers. The letters indicate the major groups the factors belong. The second letters show the phase. And the number that comes third or second indicate the list of serial for the specific factors. For Example, AA1 the first A for Client, the second A to show phase of feasibility and pre-design. This clearly seen in the appendix 1 .

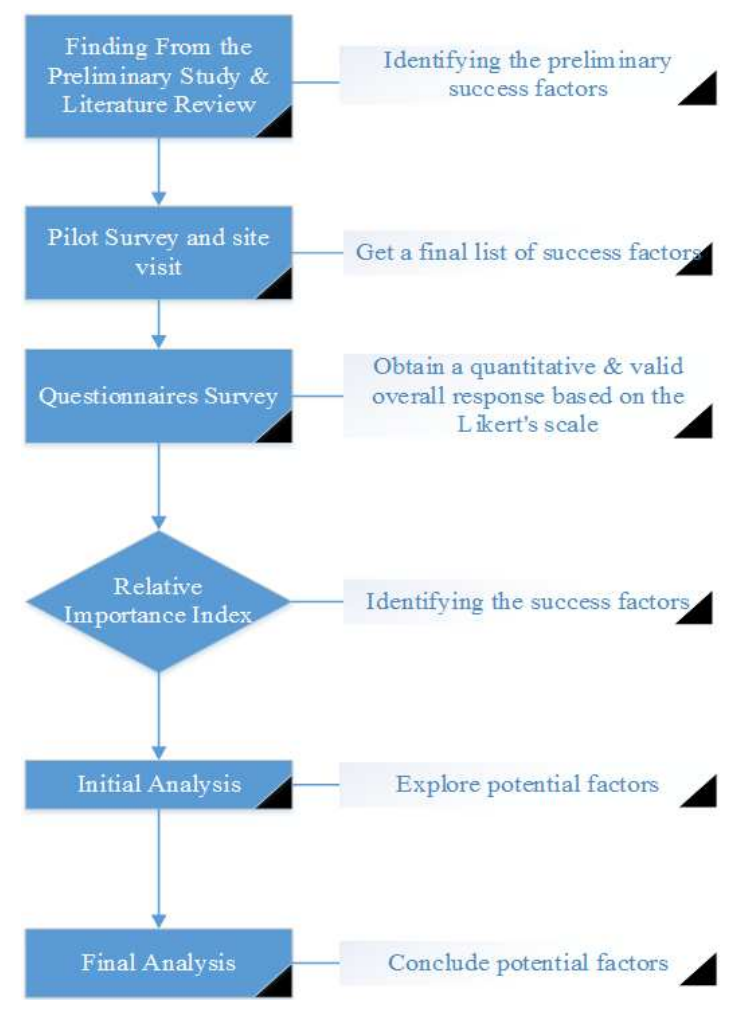

Figure 5. Flow of Analysis.

The second step is describing and summarizing the information and response into excel.

The third step is analyzing frequency, mean, Reliability test (Cronbach's alpha) and Relative Importance Index.

$$
\begin{gathered}
\mathrm{RII}=\frac{\sum W}{A * N} \\
=\frac{5 n_{5}+4 n_{4}+3 n_{3}+2 n_{2}+1 n_{1}}{A * N}
\end{gathered}
$$

Where:

RII $=$ Relative Importance Index

$\mathrm{W}=$ Weight given to each factor by the respondents $(1-5)$

$\mathrm{A}=$ Highest weight; in our case 5

$\mathrm{N}=$ Total number of respondents

RII is used to rank different success factors. It enable to cross compare the relative importance of the factors as perceived by different respondents. It enables to assess the general and an overall ranking in order to give big picture.

\subsection{Scale Reliability, Validity and Ethical Considerations}

Reliability is the extent of how reliable is the said measurement model in measuring the intended latent construct. Inter-Item reliability test applied as multiple items questionnaires used to measure a single concept. Reliability analysis was carried out for internal consistency with regard to respondent's data using Cronbach's alpha.

$$
\text { Cronbach's alpha }=\frac{K}{K-1}\left(1-\frac{\sum S^{2} y}{S^{2} x}\right)
$$

Where $K$ is Items/ questions components $\sum S^{2} y$ is Sum of items variance $S^{2} x$ is Variance of total scores

From the analysis the following result found.

Table 12. Result.

\begin{tabular}{ll}
\hline Items/ questions components & 82 \\
Sum of items variance & 74.68833 \\
Variance of total scores & 2504.516 \\
Cronbach's Alpha & 0.982156 \\
\hline
\end{tabular}

Source: Own computation, 2021.

Table 13. Ranges of validity for Cronbach's Alpha.

\begin{tabular}{ll}
\hline Cronbach's Alpha & Internal consistency \\
\hline $0.90 \&$ above & Excellent \\
$0.8-0.89$ & Good \\
$0.7-0.79$ & Acceptable \\
\hline
\end{tabular}

Source: Cronbaches-alpha-SPSS.

Our Cronbach's Alpha result which is 0.982 is excellent in its internal consistency.

Validity: Firstly, I do have a prior experience and educational background and currently working as a Civil Work Engineer. I used reference of renowned literature in all aspects of my research. To ensure validity questioners were reviewed by my advisor and project management professionals before distributing to the respondent about its relevance.

Ethical Consideration: Since the data collection technique is questionnaires consideration for the comfort of respondents are needed. To get willingness a friendly approach of communication implemented. Cover letter of questionnaires assures that by clearly stating the purpose and aim of research. The purpose of survey is entirely academics and the participation is voluntarily. Respondents provided with all the relevant information. This process further ensured that the study will not misbehave the behavioral norms of respondents or their representing organization. In addition, findings were reported in an honesty fashion, without misrepresenting any responses or intentionally misleading readers and researchers.

\section{Result and Discussion}

\subsection{Response Rate}

To avoid bias regarding response among the participants' outcome the response rate is necessary. It also indicates the quality of the survey and how the survey covered the expected sample size. The questionnaires sent for respondents is 85 (SS) and the answered survey back is 60 . 


$$
\begin{aligned}
\text { Response Rate } & =\frac{\text { Answered survey }}{\text { Sent Questionnaires }} * 100 \\
& =\frac{60}{85} * 100=70.06 \%
\end{aligned}
$$

For data collection In-Person survey from infographic data the minimum average Response Rate is $57 \%$. Our result is $70.06 \%$ which is enough and satisfactory.

\subsection{Demographic Data}

Age of respondents is used for the sake of having some realistic image with respect to their work experience and position they held. Demographic data provided deals with important issues related to purpose of research. First, it helps to support validity of data. Moreover, all respondents deal directly with mixed use building construction projects and have direct educational background to the study. Experience of respondents is a good indicator of sample precision. In addition, Respondents Working/Representing shows that inclusiveness of stakeholders is achieved. From all four stakeholders significant and almost equal response is collected.

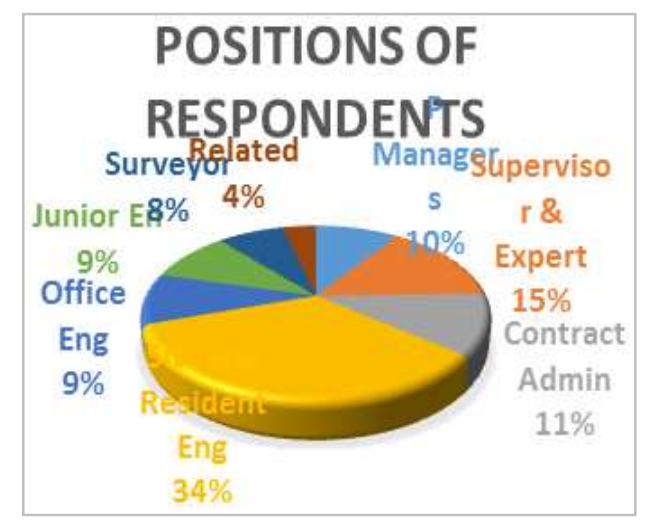

Figure 6. Demographic Data.

\subsection{Finding and Discussion}

This section focuses on the analysis of data collected. This sections developed in the manner of answering the research question:

1) What are the potential success factors of mixed use building construction project in Arada Sub-city, Addis Ababa?

2) Which factors are the most significant? What are their ranks relative to others factors? Which factors are less significant?
3) To what major categories they belong and on which phases of construction?

\subsubsection{Factors Group Discussion}

This part comes to generalize the findings of success factors on major groups of success factors in mixed use building construction projects in Arada Sub-city, Addis Ababa. It aims to clarify a priority for construction based on the result of collected questionnaires.

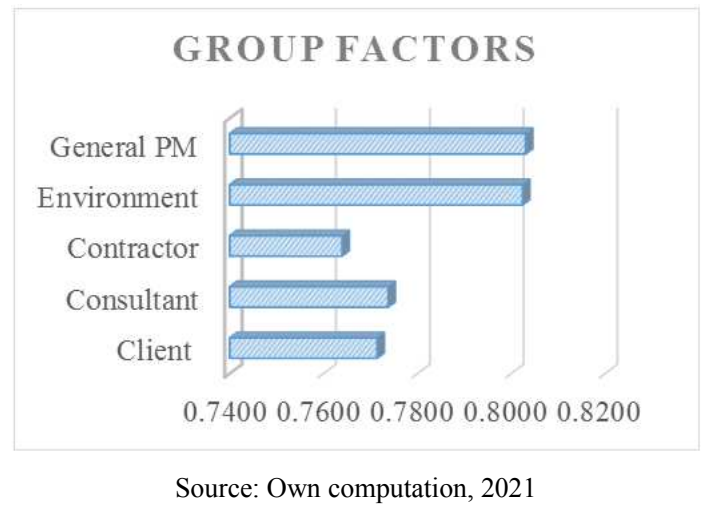

Figure 7. Factors category rank based on RII.

General Project management Practices Related success factors becomes the leading from the remaining major success factor group.

\subsubsection{General Project Management Practice Related Success Factors}

From the figure 7 General Project Management related factors have most significant impact for the success of project. This major group of success factors is more general and shared by all stakeholder and to be considered in each phase of construction from the initiation of project to the closure of the project. More of about the culture of work within the organization of each stakeholder, skills and techniques. Those factors oriented on the techniques and organizational aspect which applied during the whole project life cycle by all stakeholders. This group of success factors need a highest attention by all participant for the successful achievement of the project. Project management action is a key for the success of construction project. The selected variables under General Project management practices have a significant impact for the success of project. All stakeholder agreed and gave highest grade. So, stakeholders on those project should have to clearly understand which aspects of variables have significant effect and which one is less.

\begin{tabular}{|c|c|c|c|}
\hline Code & Descriptions & RII & Rank \\
\hline E1 & Lessons learned from previous project & 0.863 & 1 \\
\hline E9 & Qualified and specialized personnel & 0.841 & 2 \\
\hline E4 & Conducting On-job research & 0.830 & 3 \\
\hline E7 & Good documentation \& open communication & 0.827 & 4 \\
\hline E6 & Adequate experience in construction & 0.823 & 5 \\
\hline E2 & Better cooperation and relationship & 0.817 & 6 \\
\hline E3 & Frequent \& consistent decision & 0.810 & 7 \\
\hline
\end{tabular}

Table 14. RII Result for General Project Management Success factors. 


\begin{tabular}{llll}
\hline Code & Descriptions & RII & \multicolumn{1}{c}{ Rank } \\
\hline E11 & Training on construction and PM & 8 & 0.793 \\
E5 & Good organizational structure & 0.793 \\
E10 & Clear responsibility demarcation and assignment & 0.787 & 0.783 \\
E13 & Reward and recognition & 10 & 0.753 \\
E5 & Applying modern construction tools, techniques and methodology & 11 \\
E12 & Making trade-off on projects triple constraints & 12 & 0.717 \\
\hline
\end{tabular}

Source: Own computation, 2021.

Lessons learned from previous construction project took the first rank. This illustrate that learning from the past and setting remedial solution for future is key for success of project $\&$ help to avoid repeatedly doing same mistake. This will incorporate problem faced, remedial solution taken \& new achievement.

Having qualified and specialized personnel on required area took the second rank. Specially for consultant and contractors acquiring those required professionals is essential for the successful achievement of the project.

Conducting On-job research to find remedial solution have been ranked third. This will enable workers to cope up with new knowledge and information external to the organization while conducting the research. The knowledge gained through such activities highly improves the success of project by providing a learning platforms for junior and other worker and save time and money invested for training purpose.

Good documentation, detailed procedure and open communication ranked as a fourth. Procedure and manuals are the pre-indicator of the project success. Having those things well documented will make the overall activities easy for workers by guiding them. In addition, exercising free flow of information will make the working process continuity good by avoiding misunderstanding.

Having experience make the professional for executing new project by making them familiar. As construction needs a team work better cooperation among stakeholders or working units ranked sixth significant factors. Also decision to be made should have to be frequent, tough and consistent.

\subsubsection{Environment Related Success Factors}

Environment includes social, political, natural and technical systems. Variables under environment are most potential as controlling them is beyond the capacity of project stakeholders. Providing advanced risk identifications or mitigation plan is necessary. Environment changes have direct impact on project. Those factors may promote or hinder the project. All phases of project \& all stakeholders are influenced by the environment. This group of success factors also need a highest attention because those factors are external.

Table 15. RII Result for External Related success factors.

\begin{tabular}{llll}
\hline Code & Description & RII & Rank \\
\hline D2 & Consistency of currency price \& national economy & 0.833 & 1 \\
D9 & Material and equipment availability & 0.831 & 2 \\
D10 & Financial and market stability & 0.827 & 3 \\
D6 & Predictable weather condition & 0.817 & 4 \\
D5 & Stable political condition & 0.807 & 5 \\
D1 & The industry and technology advancement & 0.800 & 6 \\
D7 & Clear and Consistent tendering law and regulation. & 0.800 & 6 \\
D3 & Skilled labor availability & 0.790 & 8 \\
\hline
\end{tabular}

Source: Own computation, 2021.

Cost is one of the triple constraint. So if there is a deviation in currency price accomplishing project with initially planned budget will be impossible. So consistency of currency price \& stability of national economy have impact. Having material \& equipment significantly increase success of project. Predictable weather condition ranked fourth.

\subsubsection{Consultant Related Success Factors}

This group ranked third. Consultant mandate in the construction project starts from understanding the interest of client and designing the project, processing tender, checking and controlling the contractors work. The below figure shows that most significant factors relating to the consultant resides under feasibility and design phase (at early start of the project). Doing proper investigations \& design will be essential. Performing adequate tender process also play significant role as per the respondents answer. During the construction phase the active regulation also required.

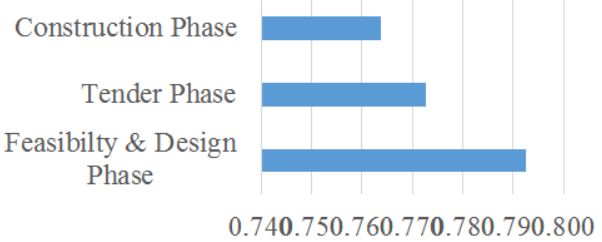

Source: Own computation, 2021

Figure 8. Consultant Related Factor On Phases. 
Table 16. RII Result for Consultant Related success factors.

\begin{tabular}{|c|c|c|c|c|}
\hline Code & Descriptions & RII & Rank & Phase \\
\hline $\mathrm{BC} 1$ & Consultant commitment to ensure construction work & 0.830 & 1 & $\mathrm{CP}$ \\
\hline BA4 & Complete drawing as per code \& Uniformity. & 0.817 & 2 & FDP \\
\hline BA1 & Collecting sufficient data \& executing required test & 0.810 & 3 & FDP \\
\hline BA3 & Familiarity with engineering cost estimation of project & 0.807 & 4 & FDP \\
\hline $\mathrm{BC} 2$ & Performing timely inspection and control & 0.797 & 5 & $\mathrm{CP}$ \\
\hline BB1 & Realistic price \& reasonable assessment of duration & 0.783 & 6 & ТР \\
\hline BB4 & Being partial and fair in evaluating contractors bid & 0.783 & 6 & ТP \\
\hline BB5 & Short bid evaluation period to avoid fluctuation & 0.783 & 6 & TP \\
\hline BB3 & Cost breakdown $\&$ considering as a means of evaluation & 0.767 & 9 & ТP \\
\hline $\mathrm{BC} 3$ & Ability to handle unexpected problems and solving disputes & 0.750 & 10 & $\mathrm{CP}$ \\
\hline $\mathrm{BC} 4$ & Proper change management & 0.750 & 10 & $\mathrm{CP}$ \\
\hline BC5 & Acceptance and approval of work on time. & 0.750 & 10 & $\mathrm{CP}$ \\
\hline BB2 & Arranging site visit for contractor & 0.747 & 13 & TP \\
\hline BC6 & Reporting and updating the status to clients & 0.747 & 13 & $\mathrm{CP}$ \\
\hline BA2 & Risk identification ability and experience & 0.737 & 15 & FDP \\
\hline $\mathrm{BC} 7$ & Intervention strategies in troubled project to recover it & 0.723 & 16 & $\mathrm{CP}$ \\
\hline
\end{tabular}

Where FDP is Feasibility and Design Phase, TP is Tender Phase, CP is Construction Phase

Source: Own computation, 2021.

Consultant commitment took the first rank. Secondly preparing Complete drawing as per design code by achieving uniformity with specification. Collecting data \& executing test also needed. Construction material to be installed and used should have to be tested. Familiarity with engineering cost estimation of project and Performing timely inspection also play a major role for success.

\subsubsection{Client Related Success Factors}

Client is mostly source of budget. Clients related variables are concerned with the characteristics of client, decision making ability \& clearly setting their interest. The analysis has ranked fourth the clients related success factor group.

The below figure shows that most significant factors relating to the client resides under feasibility and pre-design phase it means at early start of project. Doing proper feasibility is necessary. If things go wrong under this stage having remedial solutions becomes hard and the project will fail or the tradeoff and deviation will happen. Less importance is expected during the design phase of project as this stage is directly related to the consultant.

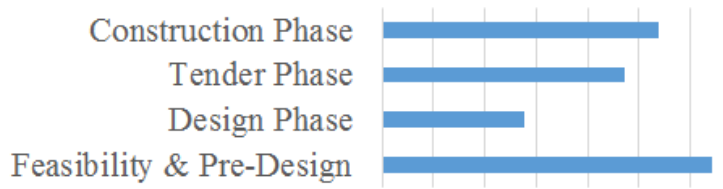

0.746 .750 .758 .760 .768 .770 .776 .780

Source: Own computation, 2021

Figure 9. Client Related Factor On Phases.

From the below table clearly defining project scope which is measurable took the first rank. Motivating contractor (award, bonus,) is necessary as it makes construction phase active and it is leading factor under client factor for Construction Phase.

Setting reasonable duration of contract period, start and end date is essential. Ability of tough decision making is also potential factor under design phases for client related success factors.

Table 17. RII Result for Client Related success factors.

\begin{tabular}{|c|c|c|c|c|}
\hline Code & Description & RII & Rank & Phase \\
\hline AA2 & Clearly defining the project scope which is measurable & 0.833 & 1 & FPDP \\
\hline $\mathrm{AD} 7$ & Motivating contractor for early finish (award, bonus) & 0.823 & 2 & $\mathrm{CP}$ \\
\hline AA1 & Having experience or skilled representatives & 0.813 & 3 & FPDP \\
\hline $\mathrm{AC} 1$ & Reasonable duration of contract period, start \& end & 0.810 & 4 & $\mathrm{TP}$ \\
\hline AD1 & Short lag time between project approval \& kick-off & 0.810 & 4 & $\mathrm{CP}$ \\
\hline AA8 & Having sufficient finance resource & 0.803 & 6 & FPDP \\
\hline AD6 & Processing payment on time & 0.803 & 6 & $\mathrm{CP}$ \\
\hline $\mathrm{AB} 3$ & Tough decision making & 0.787 & 9 & $\mathrm{DP}$ \\
\hline $\mathrm{AC} 2$ & Clear technical requirements (Measurable) & 0.787 & 9 & $\mathrm{TP}$ \\
\hline AD5 & Minimum interference and Smooth bureaucracy & 0.783 & 11 & $\mathrm{CP}$ \\
\hline $\mathrm{AC} 4$ & Tender price approach to engineering estimation than lowest & 0.770 & 12 & TD \\
\hline $\mathrm{AB} 1$ & Acceptance \& approval of drawing \& completed work & 0.770 & 12 & DP \\
\hline AD9 & Clients emphasize on quality than low cost & 0.760 & 14 & $\mathrm{CP}$ \\
\hline AD10 & Complain acceptance and management & 0.757 & 15 & $\mathrm{CP}$ \\
\hline
\end{tabular}

Where: FPDP is Feasibility \& Pre-design Phase, TD is Design Phase, DP Design Phase, CP is Construction Phase Source: Own computation, 2021. 


\subsubsection{Contractor Related Success Factor}

Contractor plays significant role for success because it executes real construction. Contractor highly shares variables of general project management practices as they more of related to the construction of the project. The below figure shows that most significant factors relating to the contractors resides under tender phases. It is unexpected result with reference to the studies so far. This shows that a big concern under tender phase needed. Understanding what is going to be done is essential and it will make the construction stage more easy.

Understanding technical requirement \& conducting site visit took first rank. This clearly shows that contractor should have to give detail attention for the tender phase as it makes construction easy by enabling contractor to do proper planning. Having high productivity rate during the construction stage ranked second.

\section{Construction Phase \\ Tender Phase \\ 0.7400 .7500 .7600 .7700 .7800 .790}

Source: Own computation, 2021

Figure 10. Contractor Related Factors.

Table 18. RII Result for Contractor Related success factors.

\begin{tabular}{|c|c|c|c|c|}
\hline Code & Description & RII & Rank & Phase \\
\hline CA1 & Understanding requirement $\&$ conducting site visit & 0.820 & 1 & TP \\
\hline CB6 & Having high productivity rate. & 0.817 & 2 & $\mathrm{CP}$ \\
\hline CB1 & Contractor experience (in year and related work) & 0.783 & 3 & $\mathrm{CP}$ \\
\hline $\mathrm{CB} 14$ & Commitment of project team & 0.777 & 4 & $\mathrm{CP}$ \\
\hline CB5 & Good site coordination and management & 0.770 & 5 & $\mathrm{CP}$ \\
\hline CA3 & Reasonable bid document preparation and submission & 0.767 & 6 & $\mathrm{TP}$ \\
\hline CB9 & Leadership and motivating skills of project manager & 0.767 & 6 & $\mathrm{CP}$ \\
\hline CA2 & Balanced and Logical cost and duration for project & 0.763 & 9 & $\mathrm{TP}$ \\
\hline CB3 & Effective scheduling and proper planning & 0.760 & 10 & $\mathrm{CP}$ \\
\hline CB7 & Proper cash flow management & 0.757 & 11 & $\mathrm{CP}$ \\
\hline CB8 & Purchasing and delivering sufficient material on time & 0.757 & 11 & $\mathrm{CP}$ \\
\hline CB4 & Efficiency, consistency and quality of sub-contractor & 0.753 & 13 & $\mathrm{CP}$ \\
\hline CB11 & Top management support and good relationship with labour & 0.750 & 14 & $\mathrm{CP}$ \\
\hline $\mathrm{CB} 2$ & Understanding bid and contract terms and conditions & 0.733 & 15 & $\mathrm{CP}$ \\
\hline
\end{tabular}

Where TP is Tender Phase and CP is Construction Phase Source: Own computation, 2021.

\subsubsection{Top 15 Single Success Factors Based on Their RII Result}

Table 19. Top 15 Single Success Factors.

\begin{tabular}{|c|c|c|c|c|c|}
\hline Code & Descriptions & RII & Rank & Group & Phase \\
\hline E1 & Lessons learned from previous construction project & 0.863 & 1 & GPM/ All Phase & \\
\hline E9 & Qualified and specialized personnel on required area & 0.841 & 2 & GPM / All Phase & \\
\hline AA2 & Clearly defining measurable project scope & 0.833 & 3 & Client & FPDP \\
\hline D2 & Consistency of currency price \& national economy & 0.833 & 3 & External / All Ph & \\
\hline D9 & Material and equipment availability & 0.831 & 5 & External/ All Ph & \\
\hline E4 & On-job research to find remedial solution. & 0.830 & 6 & GPM / All Phase & \\
\hline $\mathrm{BC} 1$ & Consultant commitment to ensure construction work & 0.830 & 6 & Consultant & $\mathrm{CP}$ \\
\hline E7 & Good documentation, procedure \& communication. & 0.827 & 8 & GPM/ All Phase & \\
\hline AD7 & Motivating contractor for early finish (award, bonus, & 0.823 & 10 & Client & $\mathrm{CP}$ \\
\hline E6 & Adequate experience in construction & 0.823 & 10 & GPM/ All Phase & \\
\hline CA1 & Understanding technical requirement \& conducting site visit & 0.820 & 12 & Contractor & $\mathrm{TP}$ \\
\hline CB6 & Having high productivity rate. & 0.817 & 13 & Contractor & $\mathrm{CP}$ \\
\hline BA4 & $\begin{array}{l}\text { Complete drawing as per design code, Uniformity \& perfect match between drawing \& } \\
\text { specification }\end{array}$ & 0.817 & 13 & Consultant & FDP \\
\hline E2 & Better cooperation and harmonies relationship among stakeholders or working units & 0.817 & 13 & GPM/ All Phase & \\
\hline
\end{tabular}

Source: Own computation, 2021.

\subsection{Interpretations and Discussions}

The findings indicate that General Project management practice related factors have significant factors for success of mixed use building construction project. This result highly agrees with research done by Munyoki S. K.[10]. The general project mangement factors for his research ranked on the top of the others major group. The sudy done by Mammaru et al. [9] also dictate the sames result regarding the General Project management practice. But when it comes to the stakeholders 
related factors this research has made a clear image by further analyzing into different phases of construction. With no doubt General Project management related factors are significant for successful implementation construction project.

Regarding the contractor related success factors most of the previous study considers the active participations of the contractor after the start of construction project. It means on construction phase. The sudy done by Mammaru et al. [9] didn't considered and investigated what are the potential factors to be implementd before the constrution phase by contractors specially during the tender stage. Of course contractors main duty is doing construction. But for the sake of understanding what to be done and giving attention under tender phase is needed. The result from this study indicate that understanding technical requirement and conducting site visit took the first rank from others variables under contractors major group. This clearly shows that the contractor should have to give detail attention for the tender phase. Understanding the requirement and conducting the site visit is becoming necessary as it makes the construction phase easily by enabling contractor to do well planning and schedule. Doing detail investigation to get enough information will save a lot of energy, time and money. It also saves the project from failures as the competent contractor take the project and saves the contractor from liquidated damages and penalty issues from client for not completing the project.

Consultant commitment to ensure construction work according to specification was the result of Babalola et al [3] research. Here the result for this study also proved that the most significant key factors from consultant is commitment. We have mentioned earlier that the consultant is like a bridge between client and contractor. Having committed consultant will maximize the chance for the success of project.

\section{Conclusion \& Recommendations}

\subsection{Conclusion}

All the aggregated factors list composed have a significant factor for the success of mixed-use building construction projects in Arada Sub-city as their RII result and professional's response clearly shows. And nothing more has been added under the open space provided to list if any more missed factors were from closed ended questions list. This clearly shows that the initially composed aggregate factors are reliable and have considered almost all the success factors. This is achieved by making detail literature review, surveying and having adequate experience in the study area.

The study found that the most important groups that affect the success of mixed use building construction project in Arada Sub-city, Addis Ababa Project are: General Project Management Related success, Environment related factors, client related factors, contractors and consultant related factors.

The most important success factors are: Lessons learned from previous construction project, Qualified and specialized personnel on required area, clearly defining the project scope which is measurable, Consistency of currency price \& national economy, Material and equipment availability, Conducting On-job research, Consultant commitment to ensure construction work according to specification, Financial and market stability,

\subsection{Recommendations}

The construction industry involves a wide range of stakeholders. Identifying those potential success factors with respect to each stakeholder will benefit a lot to do their best at each stage of the project.

There are a lot of similar processes and activities executed regularly and repeatedly within different project. Learning lessons from previous construction project and setting plan to solve problems before happening in the new project is most significant factors. It saves time and money by solving them before happening. So having well documented data from previous project and using as a reference for the new project is necessary. The lessons include problem faced and remedial solution taken.

Having qualified and specialized to ensure that the right team is developed is a pillar for the success. This expert contributes to achieve what expected. This will be a guarantee as the personnel are who runs and execute all activities. Assigning the right person to the right works and positions will yield high productivity in output at the required time in an appropriate way with a maximized quality.

Defining clearly the scope of the project that is measurable will enable to effectively proceed the overall activity according to the plan. Scope creep should have to be avoided. However, if the project faced a change that will benefit the project or mandatory situation happened applying the appropriate change management is a key factors to harmonize the initial plan with the remedy taken for the current scenario. As we know construction project intensively use construction material and different equipment. So providing enough material and equipment with required standard have great impact to increase productivity and result in success of the construction project.

Conducting On-Job research to find solutions for problems and evaluating how things are going is also essential as it promote creativity.

\subsection{Research Limitations}

While being focusing specifically on mixed use building construction in one sub-city the research is not able to provide generalization. This is the main limitations of this study since conclusion cannot be applied to other types of construction project.

\subsection{Recommendations for Further Research}

There is a high possibility of improving current study as it has limitations specially regarding generalization. By taking carrying out research on different construction project (Housing, Hotel, school) in Arada Sub-City or in others to have a big picture and to add knowledge to the existing success factors of construction project. 
The scope of the studies is limited to mixed use building construction projects, of course such types of research are realistic and easy to gather data, but to have more general result in City or Country level considering larger scope is necessary.

In addition, this research might be developed by increasing the sample size and studying the area more in depth by deploying different methodology.

\section{Abbreviations}

$\mathrm{CSF}=$ Critical Success Factors

KPI $=$ Key Performance Index
RII $=$ Relative Importance Index

$\mathrm{PM}=$ Project Management

\section{Acknowledgements}

First and foremost, I would like to owe my special thanks to the Almighty GOD, for giving me internal courage to accomplish this research. My deepest gratitude goes to my advisor, Dr Melkamu Tadesse for all the time and effort he has put into this research. I would also love to extend my thanks to all my classmates, lectures and staffs in PBTAfrica college.

\section{Appendix}

Table 20. Aggregate Success Factor List.

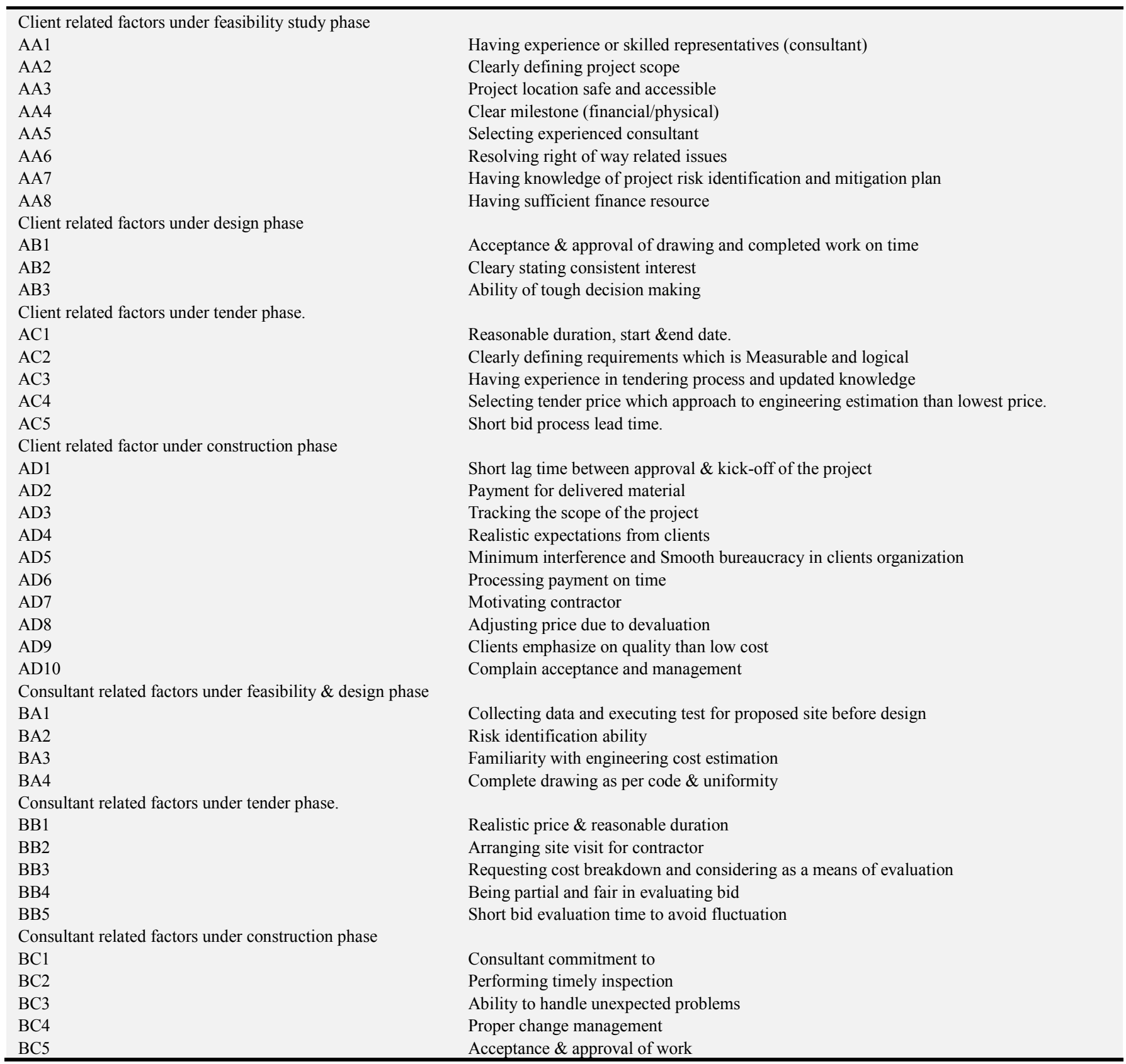




\begin{tabular}{|c|c|}
\hline BC6 & Reporting and updating the clients \\
\hline BC7 & Intervention strategies in troubled project \\
\hline \multicolumn{2}{|c|}{ Contractor related factors under tender phase } \\
\hline CA1 & Understanding technical requirement and conducting site visit \\
\hline $\mathrm{CA} 2$ & Logical cost and duration for project \\
\hline CA3 & Reasonable bid document preparation \\
\hline \multicolumn{2}{|c|}{ Contractor related factors under construction phase } \\
\hline CB1 & Contractor experience (in year \& relation) \\
\hline CB3 & Effective and proper planning, \\
\hline CB4 & Efficiency \& consistency of sub-contractor \\
\hline CB5 & Good site coordination management \\
\hline CB6 & Having high productivity rate. \\
\hline CB7 & Proper cash flow management \\
\hline CB8 & Delivering sufficient material \\
\hline CB9 & Leadership \& motivating skills of project manager \\
\hline CB11 & Top management support \\
\hline $\mathrm{CB} 12$ & Tracking work by schedule and cost performance index (SPI \& CPI) \\
\hline CB13 & Implementing health and safety program and stress management \\
\hline CB14 & Commitment of project team \\
\hline \multicolumn{2}{|c|}{ External environment related success factors } \\
\hline D1 & The industry and technology advancement \\
\hline D2 & Consistency of currency \& national economy \\
\hline D3 & Skilled labor availability \\
\hline D4 & Acceptance of project by Society \\
\hline D5 & Stable political condition \\
\hline D6 & Predictable weather condition \\
\hline D7 & Clear \& Consistent tendering law \\
\hline D8 & Short process to get work permit \& land \\
\hline D9 & Material and equipment availability \\
\hline D10 & Financial and market stability \\
\hline E2 & Better cooperation and harmonies relationship among stakeholders \\
\hline E3 & Frequent and consistent decision \\
\hline E4 & Conducting On-job research to find solution \\
\hline E5 & Good organizational structure \\
\hline E6 & Adequate experience in construction \\
\hline E7 & Good documentation and communication. \\
\hline E8 & Applying modern construction tools, techniques and methodology \\
\hline E9 & Qualified and specialized personnel \\
\hline E10 & Clear responsibility demarcation $\&$ assignment \\
\hline E11 & Training on construction and PM \\
\hline E12 & Making trade-off on projects triple constraints for no significant effect. \\
\hline E13 & Reward and recognition \\
\hline
\end{tabular}

\section{References}

[1] Alias, Z., Zawawi, E., Yusof, K., \& Aris. (2014). Determining Critical Success Factors of Project Management. AMER International Conference on Quality of Life (pp. 61 - 69). Malaysia: Centre of Studies for Construction, Faculty of Architecture Planning \& Surveying, Universiti Teknologi MARA, 40450, Shah Alam.

[2] Ayalew T, Dakhli Z and Lafhaj Z. (2016). Assessmnet on performance \& challenges of Ethiopian construction industries. Journal of Architect \& Civil Engineering, 2 (11), 01 - 11.

[3] Babalola Ifedolapo, Oluwatuyi Opeyemi, Akindoye Lawal and Aiyewalehinmi Elkanah. (2015, Oct). Factor Influencing the performance of Construction Projects In Akure, Nigeria. International Journal of Civil Engineering, Construction Management, 3 (4), 57 - 67.
[4] Chan A., Scott D. and Chan A. (2012) 'Factors affecting the success of a construction project' Journal of Construction Engineering and Management vol. 130, issue 1, p. 153-155.

[5] Cooper, D. and Schindler, P. 8th Edition (2003) Business research methods. Boston: McGraw-Hill.

[6] Davis. K. (2014). Different stakeholder groups and their perceptions of project success. International Journal of Project Management, Volume 32, Issue 2, Pages 189- 201. https://doi.org/10.1016/j.ijproman.2013.02.006

[7] Ioana Beleiu, Emil Crisan and Razvar Nistor. (2014). Main Factors Influencing Project Success. Inter-Disciplinary Management Research, 59 - 72.

[8] Kerzner. (2014). Project Management: practice and perspective. International journal of project management, vol 42 , issue 4, p. 340-419. 
[9] Mammaru Dessalegn, Esayas Alemayehu and Sintayehu Assefa. (2017, April 10). Investigation of Major Success Factors on Building Construction Projects Management System in Addis Ababa, Ethiopia. American Journal of Civil Engineering, 5 (3), 155 - 163.

[10] Munyoki, S. K. (2014). Factors Influencing Completion of Construction Project; A Case of Construction Project In Nairobi Kenya 2014. Research Paper.

[11] Nehemiah Mavetera, Kagiso Sekhabisa, Chipo Mavetera, Ireen Choga. (Autumn 2015). Factors influencing success of Construction Projects By Emerging Contractors In South Africa: A Case Of Mahikeng Area. Corporate Ownership \& Control, Issue 1,, Continued-9, 13.
[12] Nguyen T. A. and Chovichien V.. (2013). A practical list of criteria for evaluating construction project success (Vol. 21).

[13] Ticehurst, G. W. and Veal, A. J. (1999) Business research methods: a managerial approach, Australia: Longman.

[14] Tsedenya Y. (2020). Assessment of Project Implementation and Rating of Critical Factors Affecting Project Success in Construction Projects: In the case of Bamacon Engineering. Addis Ababa University, School of Commerce Addis Ababa, Ethiopia.

[15] Worku Koshe and K. N. Jha, (2016, December 2). Investigating causes of construction delay in Ethiopia construction Industries. Journal of Civil, Construction and Environmental Engineering, Vol 1 (number 1), pp 18 - 29. 